\title{
Analysis of User Resistance Towards Adopting E-Office: A Case from A Governmental Organization
}

\author{
Pandu Dwi Luhur Pambudi ${ }^{1}$ \\ ${ }^{1}$ Department of Information Systems, Institut Teknologi Sepulub Nopember, Indonesia
}

\begin{abstract}
The advancement in information technology is accelerating, affecting many industries. Government entities are one of the industries that have been affected. They adopt information technology (IT) to replace disorganized traditional business processes. This study observes that the IT innovation adoption in an organization will lead to some resistance. We bring a case of IT adoption to replace one part of a manual business process (letter management system) into a digitalized system called E-office in one of Indonesia's governmental organizations. The adoption of IT causes some resistance within the organization, which motivates us to identify resistances before and during the adoption. We interview a team who oversees handling E-office implementation and discovered two types of resistances in technology adoption: delaying resistances and opposition resistances. Meanwhile, there are two types of behavioral resistances: reluctant compliance resistance and misguided application resistance. This research further provides details on the approaches used by the organization to mitigate resistances before and during the adoption of the E-office project's implementation.
\end{abstract}

\section{CONTACT}

luhur.pandu@gmail.com

\section{KEYWORDS}

Behavioral resistance, Governmental organizations, IT adoption, Resistance to technology adoption

\section{INTRODUCTION}

Some organizations can evolve and adapt to changes, ensuring they can survive; on the other hand, some organizations are failing to adapt to the changes. Organizations and societies must evolve in tandem with the changing environment, not just to be superior, but also to thrive [1]. As a result, companies are recognizing continuous improvements as an inevitable part of the industry. Today, organizations are attempting to protect against the forces of change as the economy increasingly improves, including technological, social, and environmental considerations, as well as the employee adaptation to change [2]. Change in an organization is triggered to meet demand (i.e., high employees' productivity) by utilizing the new technology, new methodologies, new job customs, and so on. As we have seen, most of these changes are usually unwelcome to employees, who will often see them as threats to their position in the organization, resulting in resistance to change [3]. In this study, we focus on two types of resistances: 1 . Resistance to technology adoption proposed by Park [4]; and 2. Behavioral resistance proposed by Lines [9]. Resistance to technology adoption expresses itself in a variety of ways, ranging from simple rejection to strong resistance, meanwhile, we consider the behavioral resistance on employee actions, such as how employees generally respond to changes.

In this research, we examine the adoption of IT innovation in a governmental organization by taking a case of a manual business process (letter management system) replacement into a digitalized system called E-office. The new digitalized system affected 77 divisions, resulting in some internal resistance. We find a gap from the prior study which presents the analysis of user resistance towards adopting e-learning conducted by Muqtadiroh [10] by examining the resistance factors, including perceived threat, perceived usefulness, perceived inequity, and behavior intention through a structural equation model. Therefore, our study fills the gap on the qualitative study in analyzing the resistance behavior towards the adoption of technology and identify the success evidence to solve the resistance to change.

As a result, we are motivated to identify and analyze the types of resistances that emerged in response to the following research questions (RQs): 1 . What are the identified resistances existed before and during the adoption of the E-office? 2. What are the approaches to mitigate resistances? We restrict our research to the types of resistances in technology adoption since we are observing the case of IT adoption by Park [4]. In addition, we identify the types of behavioral resistances described by Lines [9] and observe the general resistances that existed in the organization. Referring to Berazneva [11], we utilize the audio recording interview method to address the RQs as the interview tool. We then interpret the interview outcomes using Conversation Analysis (CA) from Macleod [14] in Channon [12]. Finally, this study presents us how a governmental organization can be successful in dealing with resistances by verifying the approaches provided by the organization with the methods stated by Kotter [13]. 


\section{METHOD}

We begin the study by conducting a literature review by searching prior studies in journal libraries, then develop the RQs, perform the interview, and evaluate the findings. Figure 1 depicts the research flow in chronological order.

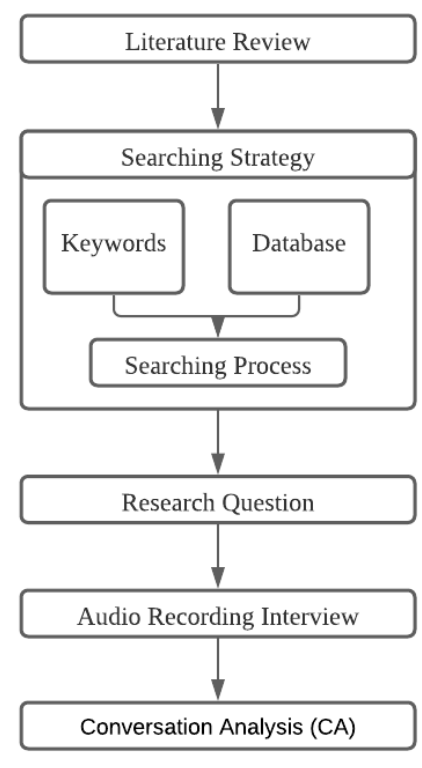

Figure 1. Research Flow

We refer to Park [4] for the resistance to technology adoption, which summarizes the list of resistances to technology adoption in Table 1 with the 9 types of resistance to technology adoption: inertia, active, strong active, rejection, delaying, opposition, apathy, passive, and aggressive. Furthermore, we then characterize 12 types of behavioral resistance by Lines [9] as defined in Table 2: reluctant compliance, delaying, lack of transparency, restricting education, arguing \& open criticism, obstructing \& subverting, spreading the negative word, termination, reversion, misguided application, forcing the change, and external influence. After successfully listed the theoretical study on the types of resistance, we thus formulating questions for the interview purpose to identify and confirm the resistances occurred before and during the adoption of E-office.

Table 1. Types of resistance to technology adoption

\begin{tabular}{ll}
\hline \multicolumn{1}{c}{ Type of resistive behavior } & \multicolumn{1}{c}{ Definition of resistive behavior } \\
\hline Inertia & People maintain the existing product, service, or practice [5] \\
\hline Active & $\begin{array}{l}\text { People take a negative position on the adoption of innovation because they consider that } \\
\text { innovation is harmful to them [5]. Including opposing innovation and asking others to } \\
\text { participate in supporting their objections [6] }\end{array}$ \\
\hline Strong active & $\begin{array}{l}\text { People blame the adoption of innovation because they consider innovation as } \\
\text { inappropriate [5] }\end{array}$ \\
\hline Rejection & $\begin{array}{l}\text { People reject to accept innovation [7], which is the strongest resistance to innovation } \\
\text { adoption [8] }\end{array}$ \\
\hline Delaying & $\begin{array}{l}\text { People delay the innovation adoption [8], or the act of waiting to adopt an innovation } \\
\text { until appropriate circumstances arise [7] }\end{array}$ \\
\hline Opposition & $\begin{array}{l}\text { People oppose innovation, which is an intermediate stage that can lead to adoption or } \\
\text { rejection [8], or an act of objection and attack on innovation [7] }\end{array}$ \\
\hline Apathy & People lack interest in the new system [6] \\
\hline Passive & People believe to keep using the old method and delay the introduction of innovation [6] \\
\hline Aggressive & People commit to doing threatening behavior, such as boycotts and strike [6] \\
\hline
\end{tabular}


Table 2. Types of behavioral resistances

\begin{tabular}{ll}
\hline \multicolumn{1}{c}{ Type of resistive behavior } & \multicolumn{1}{c}{ Definition of the resistive behavior } \\
\hline Reluctant compliance & Doing the minimum required, lack of enthusiasm, guarded and doubtful \\
\hline Delaying & Agreeing verbally but not following through, stalling, procrastinating \\
\hline Lack of transparency & Hiding or withholding useful information during implementation \\
\hline Restricting education & Avoiding or restricting the spread of the change message \\
\hline Arguing \& open criticism & Verbally opposing and/or finding fault with the change implementation \\
\hline Obstructing \& subverting & Openly sabotaging, blocking, undermining the change implementation \\
\hline Spreading the negative word & Spreading negative opinions and rumors, appealing to fear in resistance \\
\hline Termination & Voluntary or involuntary removal from the project or organization \\
\hline Reversion & Changing back to traditional practices during the implementation \\
\hline Misguided application & Changing the implementation beyond the stated process, goals, methods \\
\hline Forcing the change & Striving for perfection at expense of implementation effort \\
\hline External influence & Behavior in response to negative feedback from external sources \\
\hline
\end{tabular}

We then conduct the interview sessions. Interviews are carried out by visiting and interviewing the listed questions formulated from RQs to main interviewees, i.e., document and quality assurance (QA) staff and project manager, which we call IE1 and IE2, respectively. The interviewees are working with a software developer who responsible to handle the project implementation. The questions are grouped following RQs and focused on the 9 types of resistances to technology adoption and the 12 types of behavioral resistance. However, due to a similar type of resistance between technology adoption and behavioral resistances, i.e., delaying resistance, such that, we include delaying resistance into technology adoption and exclude it from behavioral resistance. At the end, we confirm the identified resistances with the approaches stated by Kotter [13]. We utilize the audio recording techniques during the interview process and apply the CA method to analyze the interview findings. Audio recording is immensely beneficial for detecting data holes, resolving errors, and ensuring overall quality control [11]. Furthermore, we use CA to analyze interview results since this method is ideal for interviews based on recordings and transcripts. CA reflects on taking turns, addressing mistakes or misunderstandings, how acts such as requests and questions are resolved, and how interviewees manage subjects for conversation. As a result, we conduct interviews with interviewees in three stages visit, as follows:

1. The first stage is to offer an outline of the interview objective and to inquire about project details such as project goals, project schedule, stakeholder analysis, scope, and changes made to the legacy process.

2. The second stage is used to determine whether or not there is resistance to change and how to deal with it during the project adoption period. During this visit, general RQs-related information is retrieved.

3. The final stage focuses on a more comprehensive investigation of the type of resistive behavior and methods used to resolve resistances in general. Detailed questions about the types of resistances and the approaches used to address resistances in technological innovation and behavior are questioned during this stage.

In particular, the interview findings are transcribed using a subset of the Standard Conversation Analytic Transcription Conventions as CA examined from [14] in [12].

Table 3. Standard Conversation Analytic Transcription Conventions

\begin{tabular}{ll}
\hline \multicolumn{1}{c}{ Notation } \\
\hline IE & Interviewee \\
\hline IR & Interviewer \\
\hline() & Unclear voice - unclear transcription, words are not clear - are not transcribed \\
\hline[ & Starts overlap \\
\hline$]$ & Ends overlap \\
\hline$(0.5)$ & Pause in a few seconds \\
\hline$()$. & Pause is very brief but audible \\
\hline$-(())$ & Volume increases \\
\hline$[[]]$ & Description of non-speech events \\
\hline
\end{tabular}




\section{RESULTS AND DISCUSSIONS}

In this segment, we discuss and describe the results of the interviews, as well as respond to the formulated RQs. However, we just clarify the types of resistances that have been found and place the total transcription in the Appendix. The results are then divided into two parts, as follows.

\section{Identification and Analysis of Types of Resistances (Research Question 1)}

Firstly, we identify the resistance that exists during technology adoption. Through three-stage visits, interviewees answered and clarified 9 questionnaires about resistance to technology adoption. Two types of resistances have been identified among the 9 types of resistances listed in technology adoption: delaying resistance and opposition resistance. The below are the transcripts of the interviews:

The question number (5) related to delaying resistance

IR: Question number five is (.) Is there a type of delaying resistance, such as an employee who is still looking for opportunities to postpone or procrastinate adoption, such as people who consent verbally but do not follow instructions, stall for time, or delay using new technology?

IE1: ((mumbles)) In certain situations, [[Bro]], some units initially said okay, but during adoption, they pushed the schedule back by tossing it to other units ((laughs)).

The question number (6) related to opposition resistance

IR: Let us now move on to the next issue (.) Is there a type of opposition resistance, such as when employees are reluctant to use E-office during the adoption period (i.e., before and during the adoption), and as a result, they oppose the E-office, claiming that the innovation would not perform well? It can be said that employees are between two options, to use and to not use ((laughs)) but opposing it?

IE2: ((mumbles))) Yes, [[bro]], during the early stages of adoption, some employees expressed their displeasure verbally. They contended that the manual system was superior to the digital system ((giggles)).

IR: OK ((laughs)).

We discover that there are two types of resistance during adoption: delaying resistance and opposition resistance. Delaying opposition happens both before and during adoption, for example, individuals who consent verbally (pre-adoption) but then hesitate to use the new digital system (post-adoption), stalling for time, and refusing to use E-office. Meanwhile, opposition resistance occurs when employees are reluctant and conflicted over implementing new innovative technologies. According to the analysis above, employees are opposed to the adoption, claiming that the manual system is superior to the digitalized system. Second, we list 11 types of behavioral resistance (excluding delaying resistance) to address and discover that 9 types of resistance are not identified during the adoption, with only two of them occurring, i.e., reluctant compliance and misguided application. Thus, the results of interviews are transcribed as below:

The question number (1) related to reluctant compliance resistance

IR: Is there a kind of reluctant compliance behavior during adoption, such as doing the minimum necessary on what is expected (reluctance), having less enthusiasm, putting in less effort, being cautious, and full of doubt?

IE1: ((mumbles))) (.) The transition from manual to the digital system must be achieved in stages. For example, using the current paper-based letter procedure, the employee can print the letter as a physical form, while in the E-office any single process is done systematically digitally. We have discovered that some employees are less optimistic, put in less work, and are more vigilant before and during the early stages of adoption.

The question number (10) related to misguided application resistance

IR: Is there a misguided application resistance tendency, such as altering the E-office procedure outside of the defined procedure in the manual book, including the purpose, and method? For example, do they not obey the procedure?

IE2: There were already some employees who did "the bypass" at the beginning. I recognize that when they are transitioning from a manual to a digital method, they are ignoring the user instructions in the manual book.

We observed that reluctant compliance happens when converting from manual to digital systems due to the various process flows. As a result, employees are less motivated, exert less initiative, and exercise caution before and during adoption. Meanwhile, certain employees "bypass" i.e., they do not obey the procedure or user instructions in the manual book.

\section{Approaches to mitigate the resistances (Research Question 2)}

We perform additional analysis to establish the successful execution of the E-office project. We (author and interviewees) match the identified resistive behaviors (i.e., delaying resistance, opposition resistance, reluctant compliance resistance, and misguided application resistance) with the approaches proposed by the organization to deal with resistance and confirm the approaches with the methods for managing resistance defined by Kotter [13]. 
During the interview, only four approaches were accurately identified from six change approaches. As a result, we describe the approaches in Table 4.

Table 4. Methods for dealing with resistance to change

\begin{tabular}{|c|c|c|}
\hline Approach & Type of resistive behavior & Interview questions \\
\hline $\begin{array}{l}\text { Education }+ \\
\text { communication }\end{array}$ & $\begin{array}{l}\text { Delaying resistance, opposition } \\
\text { resistance, and misguided } \\
\text { application resistance }\end{array}$ & $\begin{array}{l}\text { IR: Were there any } \\
\text { workshops, training, or } \\
\text { socialization (campaigns) to } \\
\text { foster awareness of E-office } \\
\text { adoption during the } \\
\text { adoption of E-office? }\end{array}$ \\
\hline $\begin{array}{l}\text { Participation }+ \\
\text { involvement }\end{array}$ & $\begin{array}{l}\text { Delaying resistance and } \\
\text { opposition resistance }\end{array}$ & $\begin{array}{l}\text { IR: How did the } \\
\text { participation and } \\
\text { involvement of employees } \\
\text { during the adoption of the } \\
\text { E-office? and what and how } \\
\text { the initiative was effective in } \\
\text { increasing employees } \\
\text { participation and } \\
\text { involvement? }\end{array}$ \\
\hline
\end{tabular}

Facilitation + Misguided application resistance support
IR: Was there a helpdesk or other organization-provided supports and facilitation?

\begin{tabular}{|c|c|c|c|}
\hline $\begin{array}{l}\text { Negotiation } \\
\text { agreement }\end{array}$ & & Reluctant compliance resistance & $\begin{array}{l}\text { IR: Were there any kind of } \\
\text { negotiations and agreements } \\
\text { between initiators and } \\
\text { employees before and during } \\
\text { adoption to encourage the } \\
\text { employees to start using the } \\
\text { E-office? Such as mechanisms } \\
\text { to reward and punish the } \\
\text { employees? }\end{array}$ \\
\hline
\end{tabular}

Responses

IE1: Workshops were held as part of our preparation (0.8). There was also a dedicated WhatsApp group for the leader or organizer ((laughs)) so they could quickly inquire if there were any issues with the system.

IE2: These approaches were highly effective in preventing employees from delaying, opposing, and misusing the E-office.

IE1: ((laughs)) (.) Since the initiative was directed and implemented personally by the director ((mumbles)), the employees were able to quickly follow the transition, even though some employees initially protested and delayed the adoption of E-office (.). For your information, the director of marketing and development at the Ministry of the Health Republic of Indonesia led the adoption of the E-office directly, so lower-level employees could easily jump on board due to regulations released by the initiators.

IE2: They are very supportive ((laughs))

IE1: There was a dedicated team tasked with resolving any issues that arose when using the E-office (0.3). We had customer service at all hours of the day and night, and some people even called at 9 p.m. to ask questions, so our crew had to open the laptop then ask permission to fix the issue the next day ((laughs)).

IE2: Facilitation and support are beneficial (.) in preventing staff from misguiding the E-office.

IE1: To promote rapid and extensive use of the E-office, units (.) with a high percentage of utilization rate will be rewarded; we also included a feature to assess $E$ office use using website traffic.

IE2: Rewards were very helpful in motivating workers and avoiding hesitation.

In addressing the resistance to change that exists during adoption, four approaches have been confirmed. These approaches include education + communication where there is a lack of information or inaccurate information and analysis; participation + involvement where the initiators do not have all the information, they need to design 
the change, and some have considerable power to resist; facilitation + support where people are resisting because of adjustment problems; and negotiation + agreement when someone stands to lose out from the change. Through interviews with interviewees, the four approaches were identified and analyzed.

We discovered that education + communication approaches such as workshops, training, or socialization (campaigns) are useful in promoting the use of E-office and preventing employees from delaying, opposing, or misguided in adopting E-office. Furthermore, the participation and involvement of a high-level manager (e.g., director of marketing and development) will resolve delays and opposition resistances. Besides that, through effective assistance and reward mechanisms, facilitation + support and negotiation + agreement can assist in resolving misguided application and reluctant compliance resistances.

\section{CONCLUSIONS}

We present a case of E-office digital adoption in one of Indonesia's governmental organizations, which results in some internal resistances. We identify the resistances by interviewing a team of software developers who manage the adoption. As a result, two types of resistance to technology adoption have been detected: delaying and opposition resistances. Meanwhile, two types of behavioral resistances have been recognized: reluctant compliance and misguided application resistances. Finally, we conclude that four approaches have been used by the organization to mitigate and resolve the resistances.

This research has a small number of participants, which allows for subjective responses. As a result, it is important to conduct specific interviews with more interview participants who have a direct role in the adoption (i.e., initiators and employees) to conduct a better study and verify the phenomena intensively.

\section{REFERENCES}

[1] Pakdel A. An Investigation of the Difference in the Impact of Demographic Variables on Employees' Resistance to Organizational Change in Government Organizations of Khorasan Razavi. Procedia - Soc Behav Sci 2016; 230: 439-446.

[2] Ben-Gal HC, Tzafrir SS. Consultant-client relationship: One of the secrets to effective organizational change? J Organ Chang Manag 2011; 24: 662-679.

[3] Gonçalves JM, Gonçalves RP da S. Overcoming Resistance to Changes in Information Technology Organizations. Procedia Technol 2012; 5: 293-301.

[4] Park K, Koh J. Exploring the relationship between perceived pace of technology change and adoption resistance to convergence products. Comput Human Behav 2017; 69: 142-150.

[5] Ram S, Sheth JN. Consumer resistance to innovations: The marketing problem and its solutions. J Consum Mark 1989; 6: 5.

[6] Lapointe L, Rivard S. A Multilevel Model of Resistance to Information Technology Implementation. MIS Q 2005; 29: 461-491.

[7] Kleijnen M, Lee N, Wetzels M. An exploration of consumer resistance to innovation and its antecedents. J Econ Psychol 2009; 30: 344-357.

[8] Szmigin I, Foxall G. Three forms of innovation resistance: The case of retail payment methods. Technovation 1998; 18: 459-468.

[9] Lines BC, Sullivan KT, Smithwick JB, et al. Overcoming resistance to change in engineering and construction: Change management factors for owner organizations. Int J Proj Manag 2015; 33: 1170-1179.

[10] Muqtadiroh FA, Nisafani AS, Saraswati RM, et al. Analysis of user resistance towards adopting e-learning. Procedia Comput Sci 2019; 161: 123-132.

[11] Berazneva J. FIELD REPORT AUDIO RECORDING OF HOUSEHOLD INTERVIEWS TO ENSURE DATA QUALITY †. 2014; 296: 290-296.

[12] Channon A, Foulkes P, Walker T. ' But what is the reason why you know such things ?' Question and response patterns in the LADO interview. J Pragmat 2018; 129: 154-172.

[13] Kotter JP, Schlesinger LA. Choosing strategies for change for overcoming it.

[14] Macleod NJ. Police Interviews with Women Reporting Rape : A Critical Discourse Analysis Centre for Forensic Linguistics School of Languages \& Social Sciences A thesis submitted for the degree of Doctor of Philosophy Rape: A Critical Discourse Analysis ". Thesis 2010. 
APPENDIX. Transcription conventions adapted from [14] in [12]:

A. Transcription for types of resistance in technology adoption:

The answer to the question number (1). Question regarding the type of inertia resistance.

IE1: Oh, we didn't experience it, [bro] (.) Because previously we used a manual, right ((laughs)).

The answer to the question number (2). Question regarding the type of active resistance.

IE:2 ((laughs)) we didn't face such situations, [bro]. (0.6) The user would immediately use it and adapted it to the new system.

The answer to the question number (3). Question regarding the type of strong active resistance.

IE1: (0.7) we didn't see that kind of pattern. Because they (refers to Ministry of Health) had a big budget

((laughs)), indeed they participated in the tender and budgeted that much for this project ((laughs)).

The answer to question number (4) Question regarding the rejection resistance.

IE2: ((mumbles)) (.) ((laughs)) No, [bro] we didn't experience it.

The answer to the question number (7). Question regarding the apathy resistance.

IE1: From the beginning until now there were not any pieces of evidence to that type of resistance (.), Because the board of directors asked to develop it.

The answer to the question number (8). Question regarding the passive resistance.

IE2: [[I didn't know]]

The answer to the question number (9). Question regarding the aggressive resistance.

IE1: [[No, bro]]

B. Transcription for types of behavioral resistance:

Question (2) regarding delaying resistance is merged with types of resistance in technology adoption.

The answer to the question number (3). Question regarding lack of transparency resistance.

IE1: ((mumbles)) There was nothing (0.7), it was very detailed and well-documented, [bro], there was socialization, during the transformation from manual to digital, there were indeed a lot of old generations [[uncles and aunties]], so you had to take it slow in teaching them.

The answer to the question number (4). Question regarding restricting education resistance.

IE2: ((laughs)) Wow there weren't any types of it (.), because the change led directly by the director ((mumbles))

(.) IR: What director was He?

IE2: ((mumbles)) The director of marketing and development.

The answer to the question number (5). Question regarding arguing \& open criticism resistance.

IE1: Nope, we didn't experience that ((laughs)) (0.4), the problem was more into the application procedure.

The answer to the question number (6). Question regarding obstructing \& subverting resistance.

IE2: [Wow it didn't exist], they didn't dare to do that ((laughs)).

The answer to the question number (7). Question regarding spreading the negative word resistance.

IE1: [No existing such resistances].

The answer to the question number (8). Question regarding termination resistance.

IE2: ((mumbles)) There was no such resistance (0.8), coordinators, were mostly civil servants, [마o], meanwhile, many operators have contracted employees $(0.5)$, such that they were under the rule of government policies.

The answer to the question number (9). Question regarding reversion resistance

IE1: [[Nope bro]]

The answer to the question number (11). Question regarding forcing the change resistance

IE1: Not happening there.

The answer to the question number (12). Question regarding external influence resistance. IE2: ((mumbles)) [No existing such resistances]. 